\title{
Supramolecular Tessellations via Pillar[n]arenes-Based Exo-Wall Interactions
}

\author{
Ming Li, ${ }^{\dagger, \#}$ Bin Hua ${ }^{*,{ }^{*}, \#}$ Haozhong Liang, ${ }^{\dagger}$ Jiyong Liu, ${ }^{\dagger}$ Li Shao ${ }^{*,+}$ and Feihe \\ Huang ${ }^{*}$, ,
}

'State Key Laboratory of Chemical Engineering, Center for Chemistry of High-Performance \& Novel Materials, Department of Chemistry, Zhejiang University, Hangzhou 310027, P. R. China; Fax and Tel: $+86-571-8795-3189$.

${ }^{\S}$ Green Catalysis Center and College of Chemistry, Zhengzhou University, Zhengzhou 450001, P. R. China.

Email:huabin@zju.edu.cn; lishao@zju.edu.cn; fhuang@zju.edu.cn.

\section{Supporting Information ( 24 pages)}

1. Materials and methods $\quad$ S2

2. Characterization of EtP5 and EtP6 S3

3. The structures and electrostatic potential maps of EtP6, DFN and TFB S4

4. Related multinuclear $\left({ }^{1} \mathrm{H}\right.$ and $\left.{ }^{19} \mathrm{~F}\right)$ NMR spectra of pillararenes with $\mathrm{DFN}$ and TFB

5. $U V$-vis absorption and fluorescence spectra of pillararenes with $\mathbf{D F N}$ and $\mathbf{T F B}$ in organic solvents

6. Crystal engineering of the pillararenes-based co-crystals $\quad \mathrm{S} 12$

7. References 


\section{Materials and Methods}

Materials

All chemicals and reagents including DFN and TFB were commercially available and used as supplied without further purification. Solvents were either employed as purchased or dried according to procedures described in the literature. Compounds EtP5 and EtP6 were synthesized according to previous literature procedures. ${ }^{\mathrm{S} 1}$ EtP5 was recrystallized from tetrahydrofuran and dried under vacuum. EtP6 was recrystallized from acetone and dried under vacuum. ${ }^{\text {S2 }}$

Methods

Solution NMR. Solution ${ }^{1} \mathrm{H}$ NMR spectra were recorded with a Bruker Avance DMX 600 spectrometer, a Bruker Avance DMX 500 spectrometer, or a Bruker Avance DMX 400 spectrometer using the deuterated solvent as the lock and the residual solvent or TMS as the internal reference. Solution ${ }^{19} \mathrm{~F}$ NMR spectra were recorded at $600 \mathrm{MHz}$ using a Bruker Avance $600 \mathrm{NMR}$ spectrometer. 2D NOESY NMR spectra were collected on a Bruker Avance DMX 500 spectrometer with internal standard TMS.

UV-Vis Spectra: UV-vis absorption spectra were taken on a Shimadzu UV-2550 UV-vis spectrophotometer.

Fluorescence Spectra: The fluorescence experiments were conducted on a RF-5301 spectrofluorophotometer (Shimadzu Corporation, Japan).

Electrostatic potential surface (EPS) measurements: All calculations were performed by B3LYP DFT under Gaussian G09. All structures were optimized using 6-31G(d) basis set and then ESP were calculated using 6-311G(d,p) basis set. The 3D structures were drawn by VESTA. ESP cubes were generated by Multiwfn code and plotted by VDW software. ${ }^{\mathrm{S}}$

Single Crystal X-ray Crystallography: Single crystal X-ray data sets were measured on a Rigaku MicroMax-007 HF rotating anode diffractometer (Mo-K $\alpha$ radiation, $\lambda=0.71073 \AA$, Kappa 4-circle goniometer, Rigaku Saturn 724+ detector). 
2. Characterization of EtP5 and EtP6

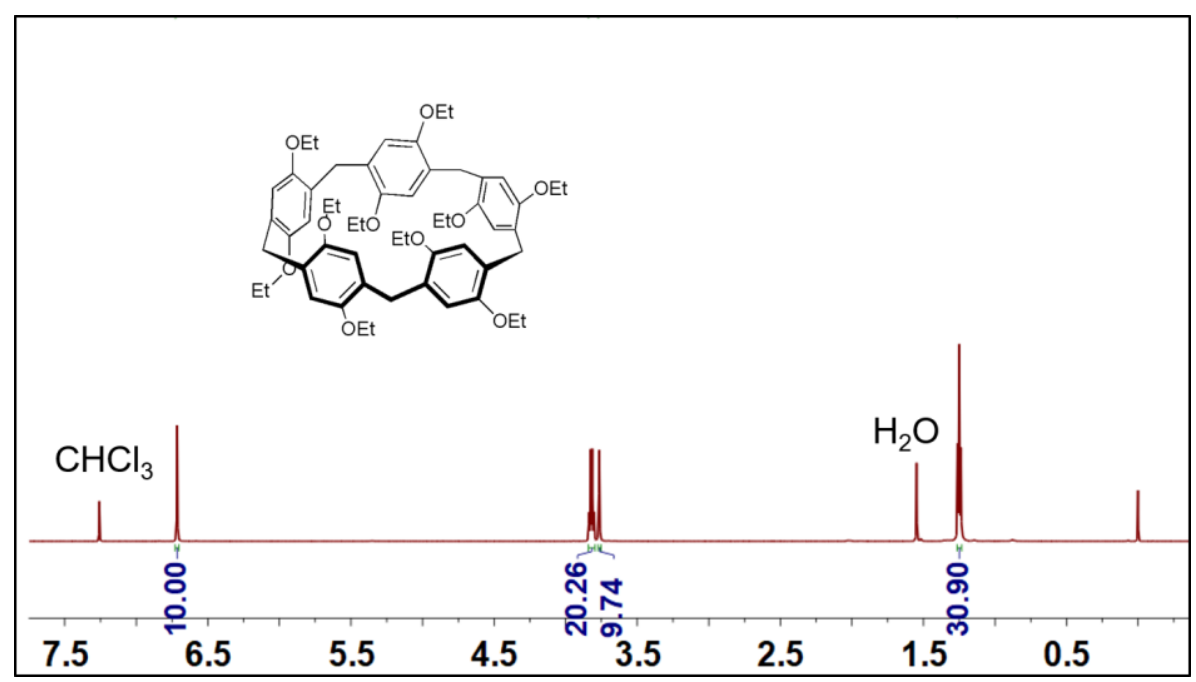

Figure S1. ${ }^{1} \mathrm{H}$ NMR spectrum ( $600 \mathrm{MHz}, \mathrm{CDCl}_{3}$, room temperature) of EtP5.

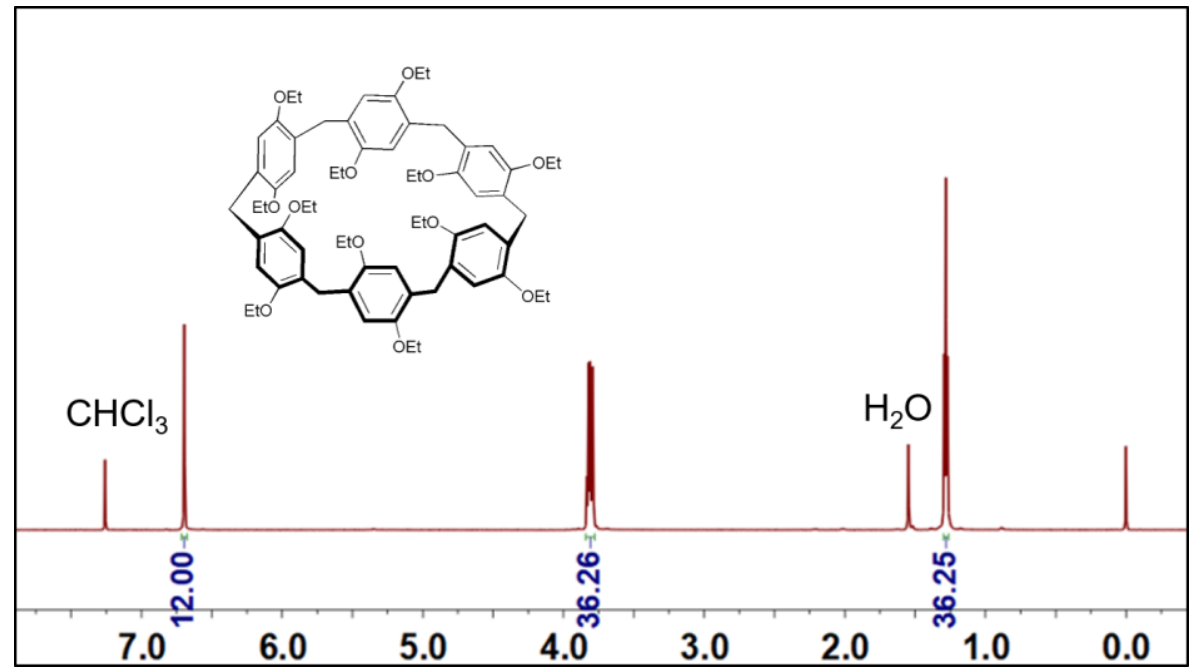

Figure S2. ${ }^{1} \mathrm{H}$ NMR spectrum ( $600 \mathrm{MHz}, \mathrm{CDCl}_{3}$, room temperature) of EtP6. 
(a)

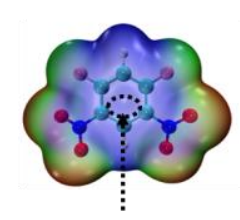
0.045

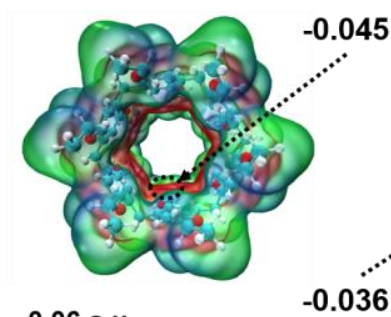

-0.06 a.u.

0.045

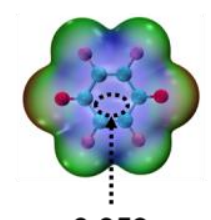

0.059

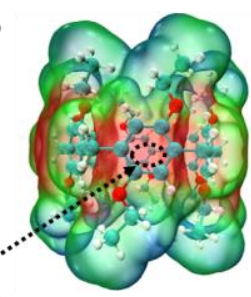

0.06 a.u.

(b)

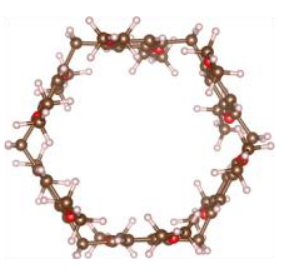

Top view

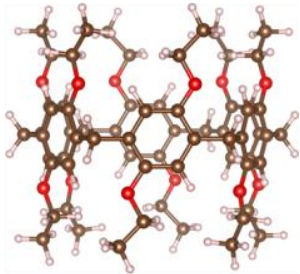

Side view

Figure S3. (a) The electrostatic potential maps of EtP6, DFN and TFB. Areas of low potential, red, are characterized by an abundance of electrons. Areas of high potential, blue, are characterized by a relative absence of electrons; (b) The rigid and regular structure of EtP6 as ideal tiling units for hexagonal tessellations.

From the electrostatic potential maps of DFN and TFB, we discovered that the area of their benzene ring part was more electropositive ( 0.045 a.u. and 0.059 a.u., respectively). While for the electrostatic potential of EtP6, the regular hexagonal aromatic wall is highly electronegative ( -0.036 a.u.), and thus the "exo-wall" of hexagonal EtP6 should be inclined to interact with relative positively charged species. From the above analysis, it can be inferred that the parallel combination strategy of the regular hexagonal aromatic wall and small molecules was feasible. ${ }^{\mathrm{S} 4}$ 
4. Related multinuclear $\left({ }^{1} \mathrm{H}\right.$ and $\left.{ }^{19} \mathrm{~F}\right)$ NMR spectra of pillararenes with $\mathrm{DFN}$ and TFB
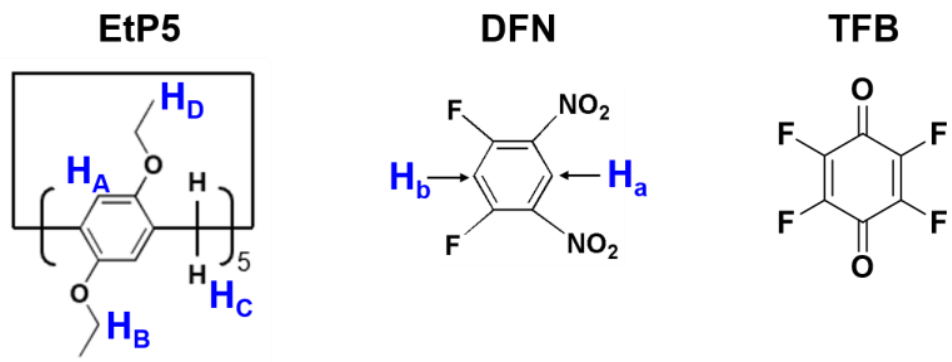

EtP6

Figure S4. Chemical structures of EtP5, DFN, TFB and EtP6.

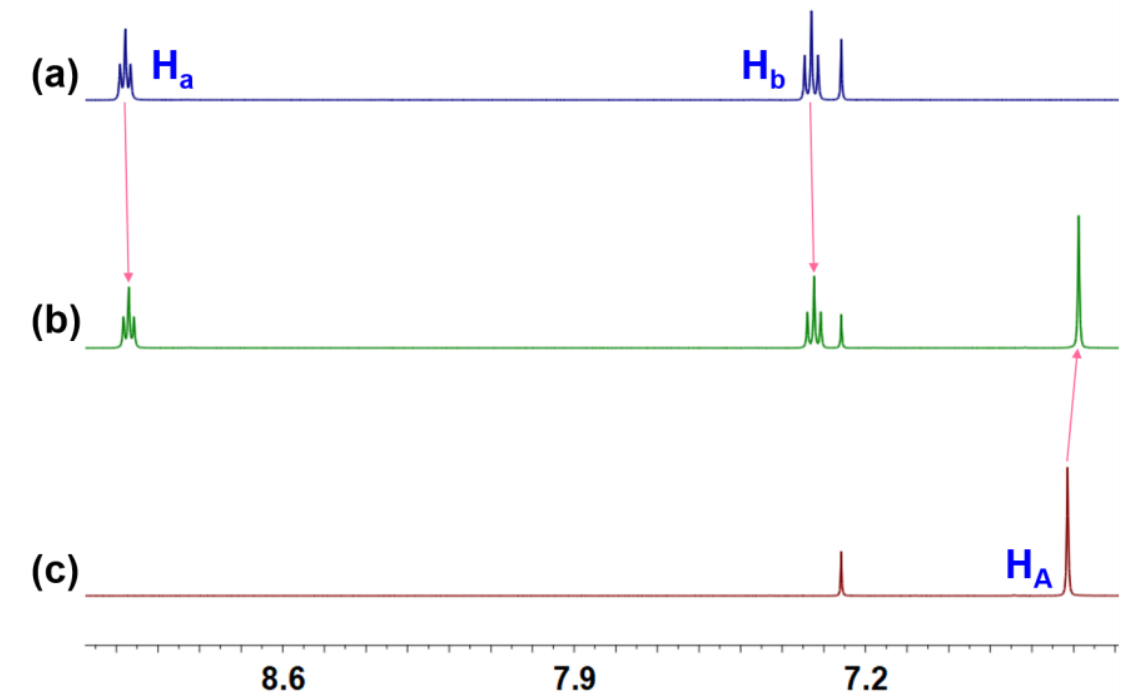

Figure S5. Partial ${ }^{1} \mathrm{H}$ NMR spectra $\left(600 \mathrm{MHz}, \mathrm{CDCl}_{3}\right.$, room temperature): (a) DFN; (b) the assemblies of EtP5 $(20 \mathrm{mM})$ and DFN $\left(1.60 \times 10^{2} \mathrm{mM}\right)$; (c) EtP5. 


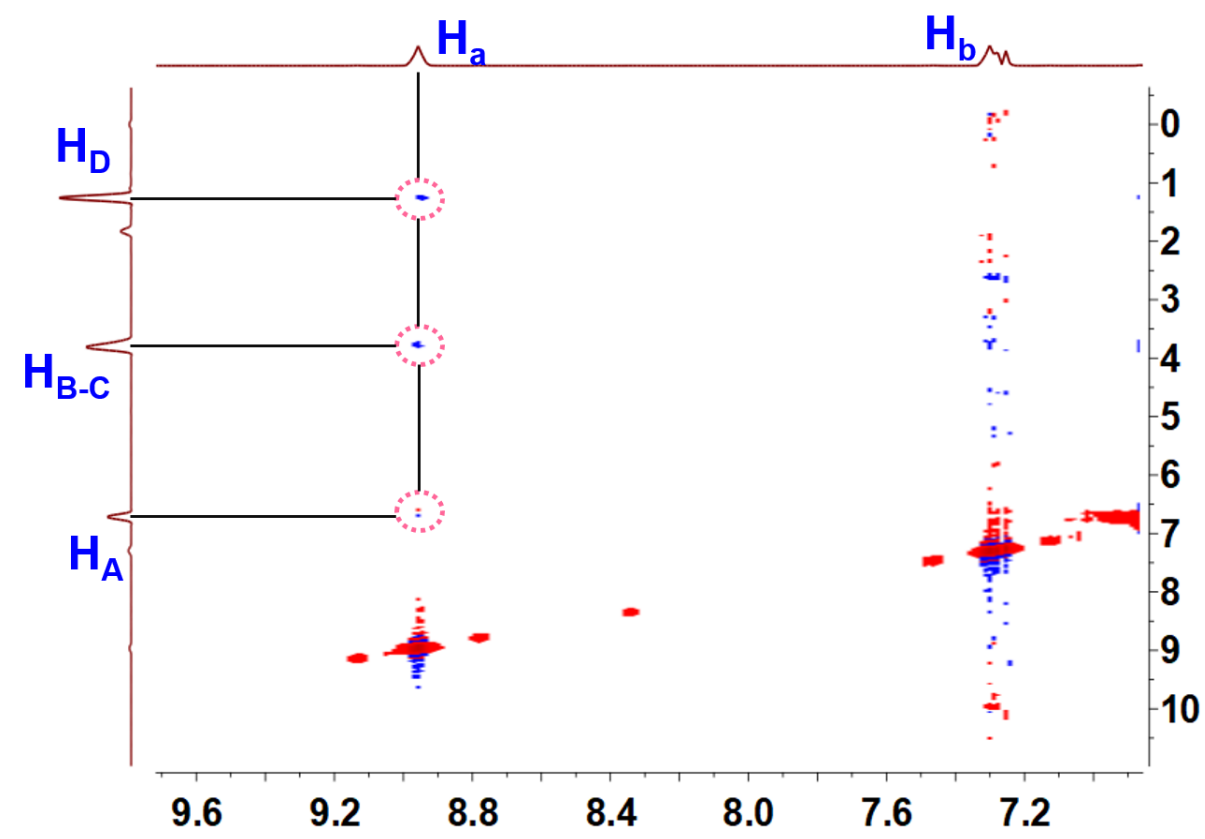

Figure S6. Partial 2D ${ }^{1} \mathrm{H}-{ }^{1} \mathrm{H}$ NOESY spectra $\left(500 \mathrm{MHz}, \mathrm{CDCl}_{3}, 298 \mathrm{~K}\right)$ of an equimolar mixture of EtP5 (20.0 mM) and DFN (20.0 mM).

(a)

(b)

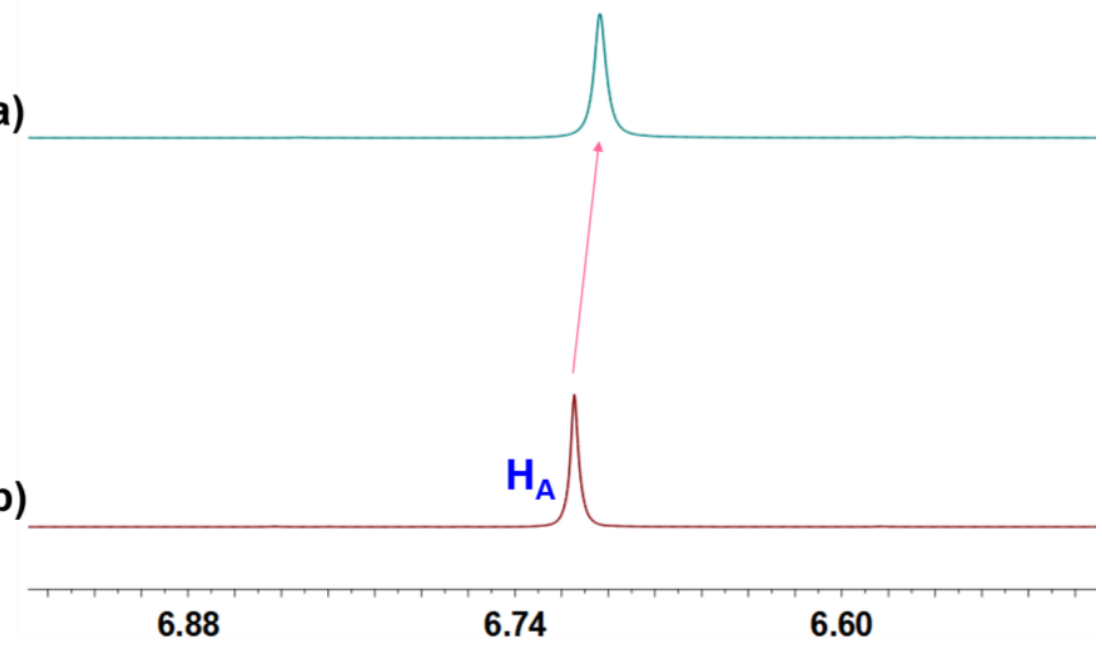

Figure S7. Partial ${ }^{1} \mathrm{H}$ NMR spectra (600 $\mathrm{MHz}, \mathrm{CDCl}_{3}$, room temperature): (a) the assemblies of EtP5 (20 mM) and TFB (80 mM); (b) EtP5. 
(a)

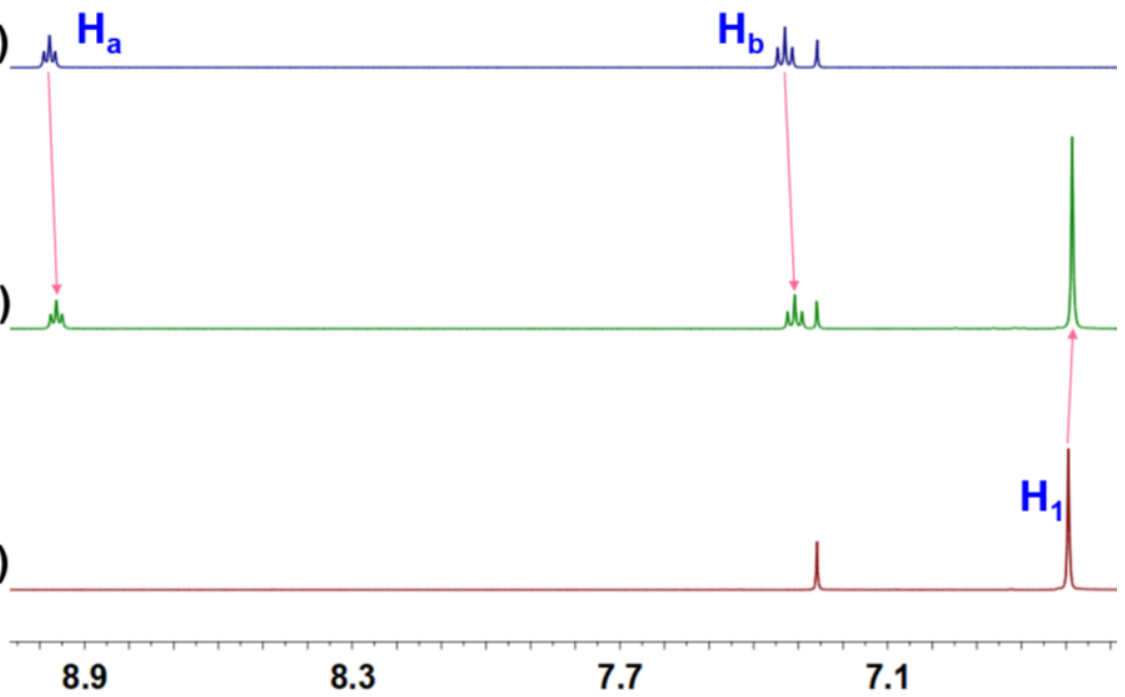

Figure S8. Partial ${ }^{1} \mathrm{H}$ NMR spectra ( $600 \mathrm{MHz}, \mathrm{CDCl}_{3}$, room temperature): (a) DFN; (b) the assemblies of EtP6 (20 mM) and DFN (80 mM); (c) EtP6.

(a)

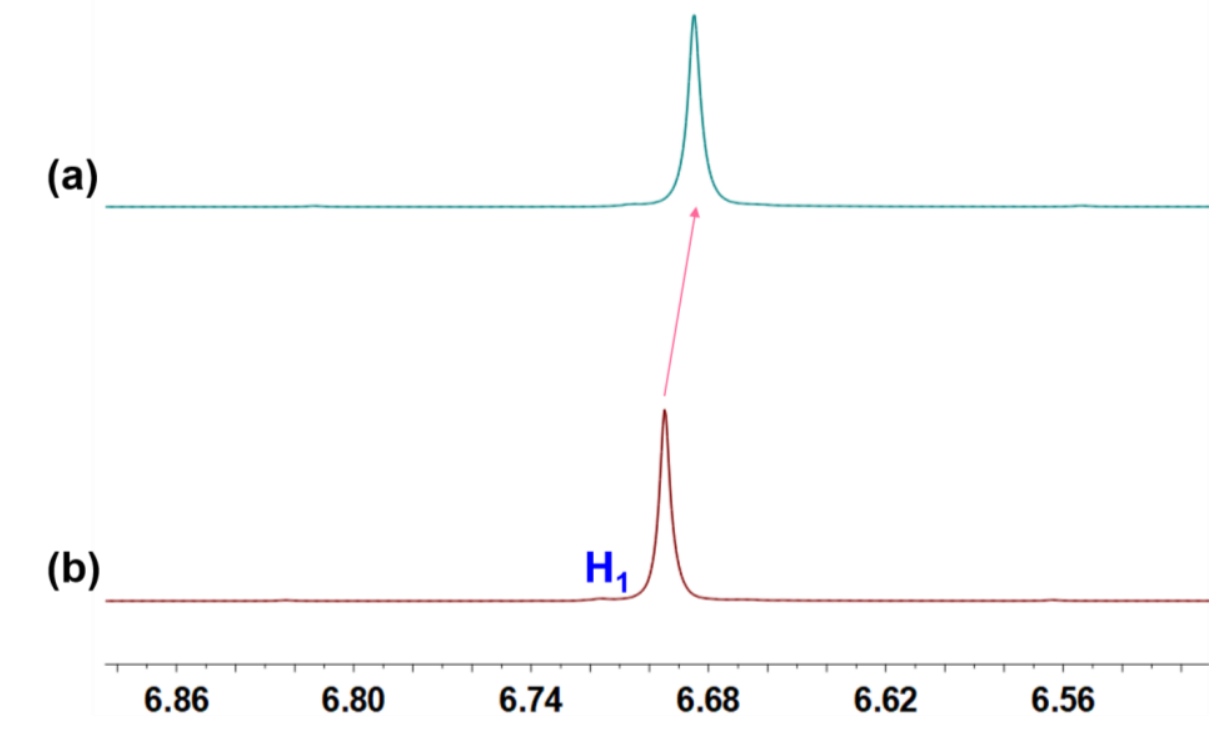

Figure S9. Partial ${ }^{1} \mathrm{H}$ NMR spectra ( $600 \mathrm{MHz}, \mathrm{CDCl}_{3}$, room temperature): (a) the assemblies of EtP6 (20 mM) and TFB (80 mM); (b) EtP6. 
(a)

(b)

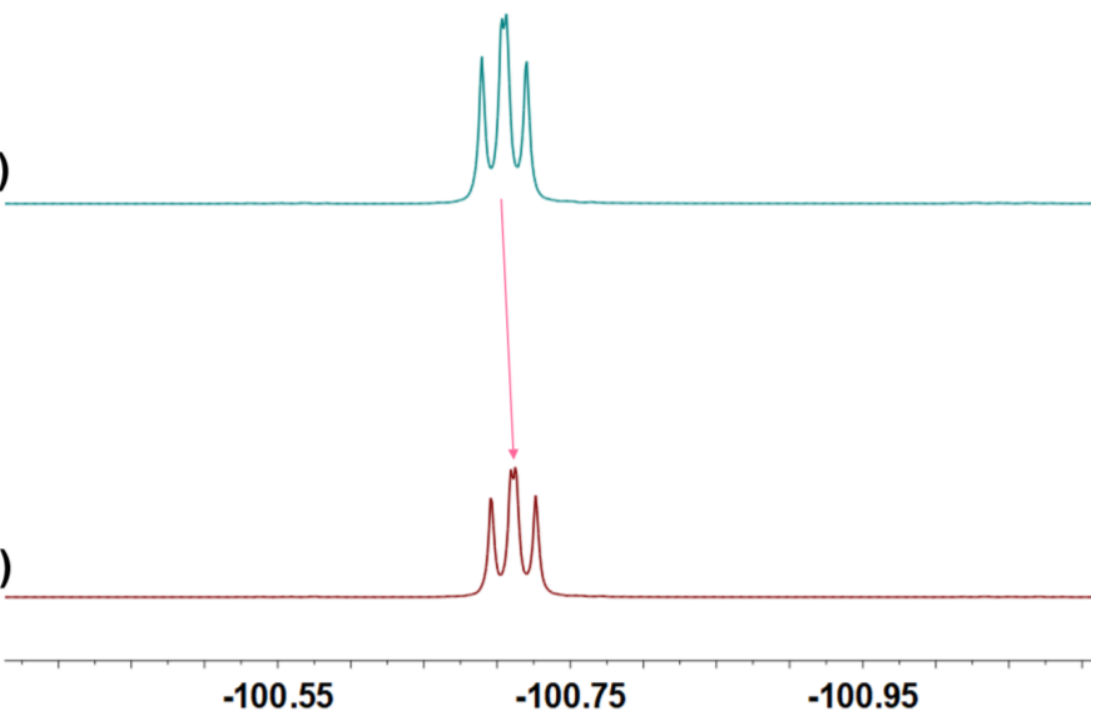

Figure S10. ${ }^{19} \mathrm{~F}$ NMR spectra $\left(564.6 \mathrm{MHz}, \mathrm{CDCl}_{3}\right.$, room temperature): (a) DFN; (b) the assemblies of EtP5 $(20 \mathrm{mM})$ and DFN $\left(1.60 \times 10^{2} \mathrm{mM}\right)$.

(a)

(b)

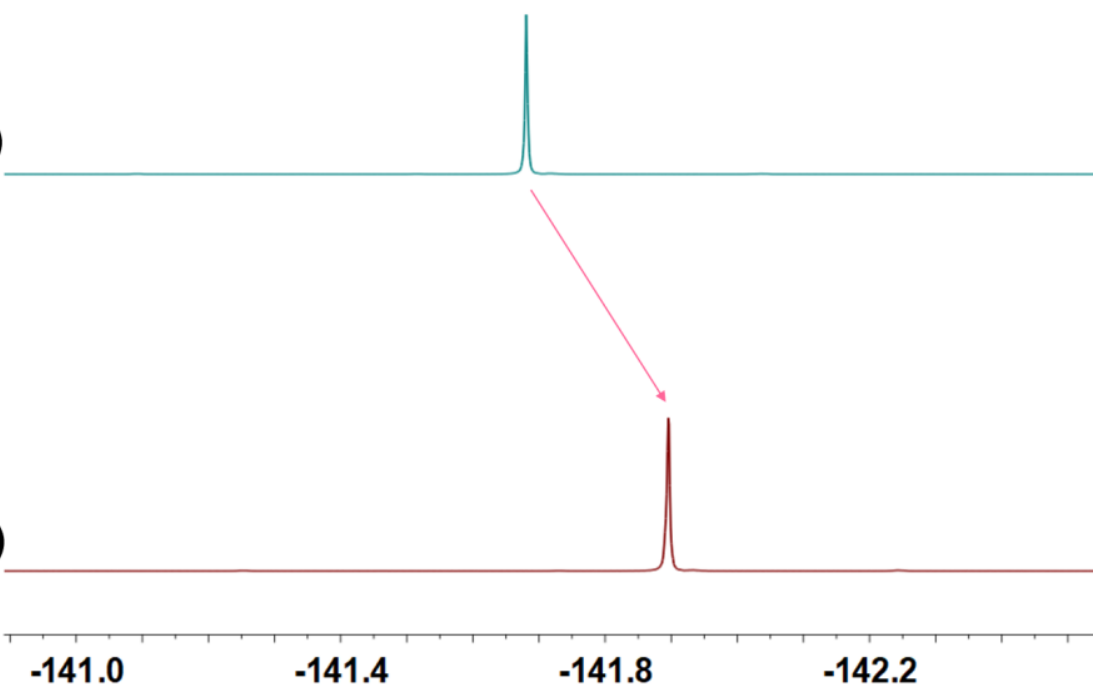

Figure S11. ${ }^{19} \mathrm{~F}$ NMR spectra $\left(564.6 \mathrm{MHz}, \mathrm{CDCl}_{3}\right.$, room temperature): (a) TFB; (b) the assemblies of EtP5 (20 mM) and TFB (80 mM). 
(a)

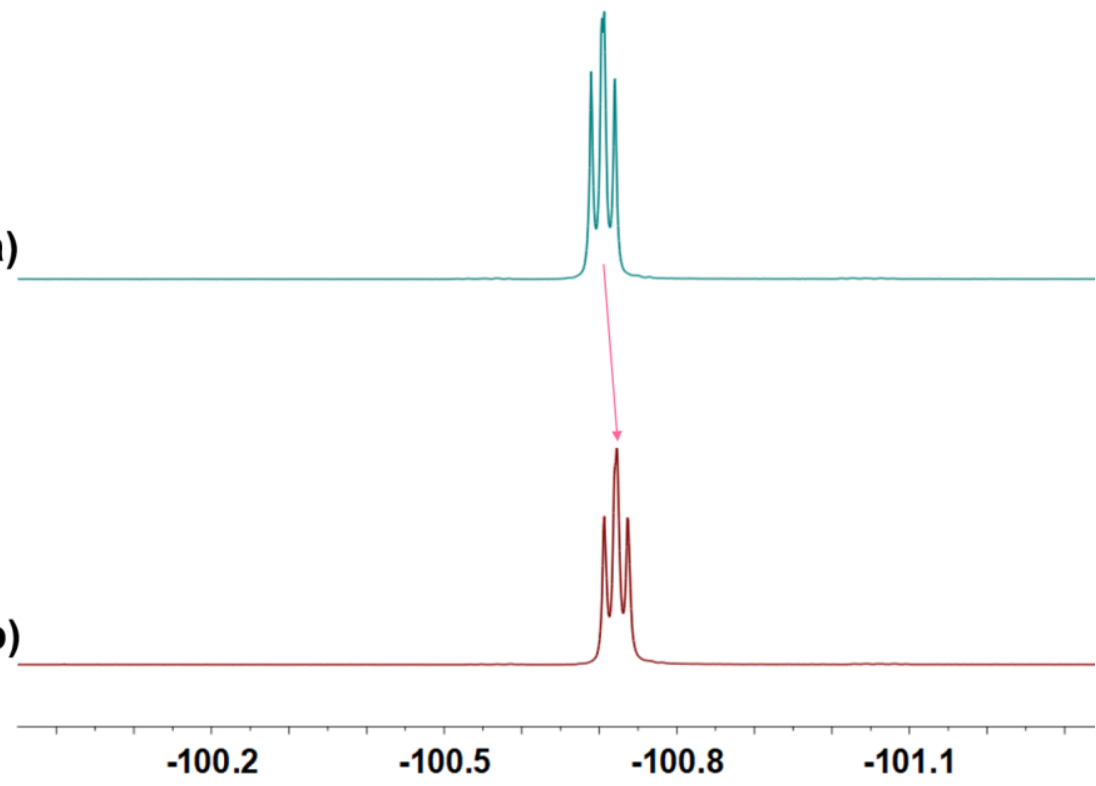

Figure S12. ${ }^{19} \mathrm{~F}$ NMR spectra $\left(564.6 \mathrm{MHz}, \mathrm{CDCl}_{3}\right.$, room temperature): (a) DFN; (b) the assemblies of EtP6 (20 mM) and DFN (80 mM).

(a)

(b)

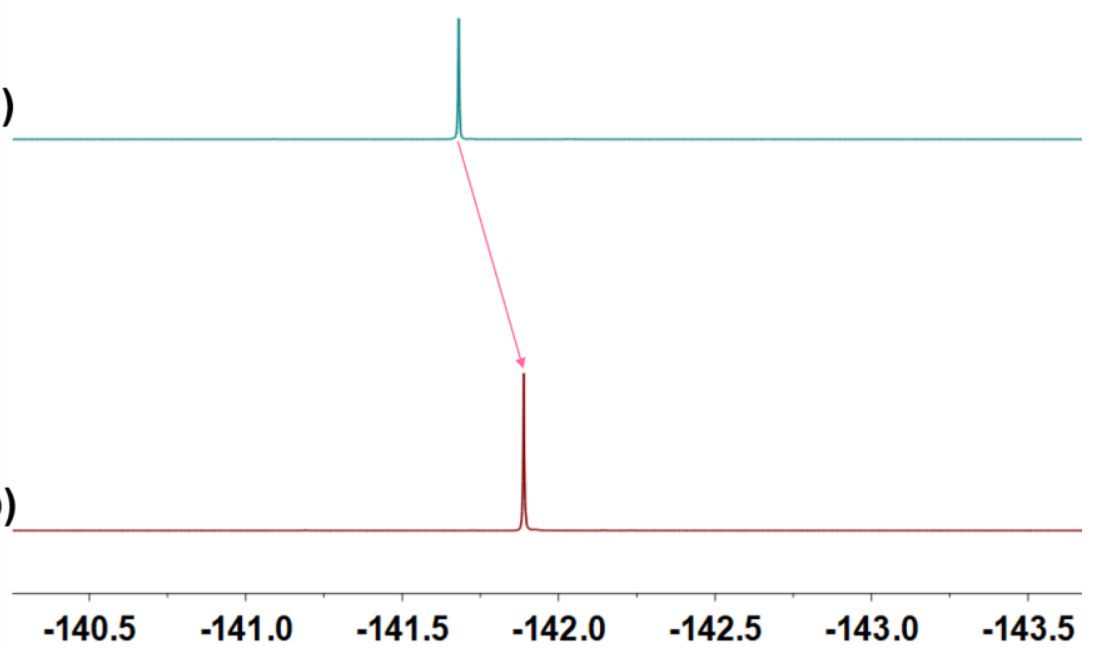

Figure S13. ${ }^{19} \mathrm{~F}$ NMR spectra $\left(564.6 \mathrm{MHz}, \mathrm{CDCl}_{3}\right.$, room temperature): (a) TFB; (b) the assemblies of EtP6 $(20 \mathrm{mM})$ and TFB $(80 \mathrm{mM})$. 
5. UV-vis absorption and fluorescence spectra of pillararenes with $\mathbf{D F N}$ and $\mathbf{T F B}$ in organic solvents
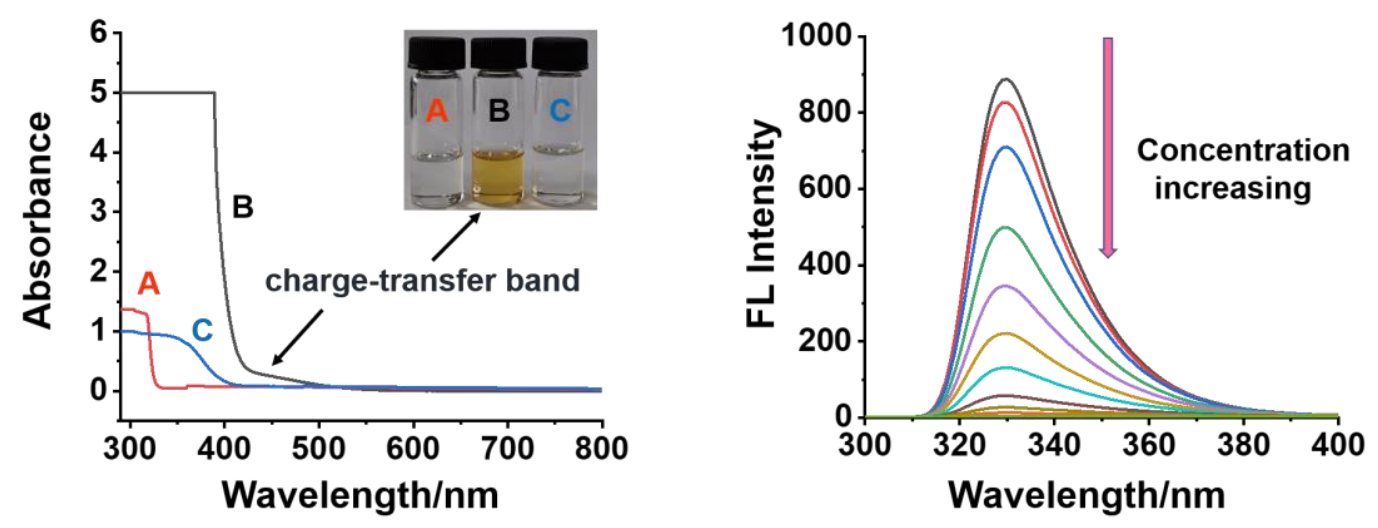

Figure S14. (a) UV-vis spectra (chloroform): A, EtP5 (0.01 M); B, DFN (0.03 M) in the presence of EtP5 (0.01 M); C, DFN (0.03 M). The inserted optical image shows the solution color change upon the formation of charge-transfer assemblies from EtP5 and DFN. (b) Fluorescence titration $\left(\lambda_{\mathrm{ex}}=280 \mathrm{~nm}\right)$ of $\mathbf{E t P 5}(1.00 \mathrm{mM})$ in $\mathrm{CH}_{2} \mathrm{Cl}_{2}$ at room temperature upon a gradual increase in the concentration of DFN (from 0 to $5.95 \mathrm{mM}$ ).
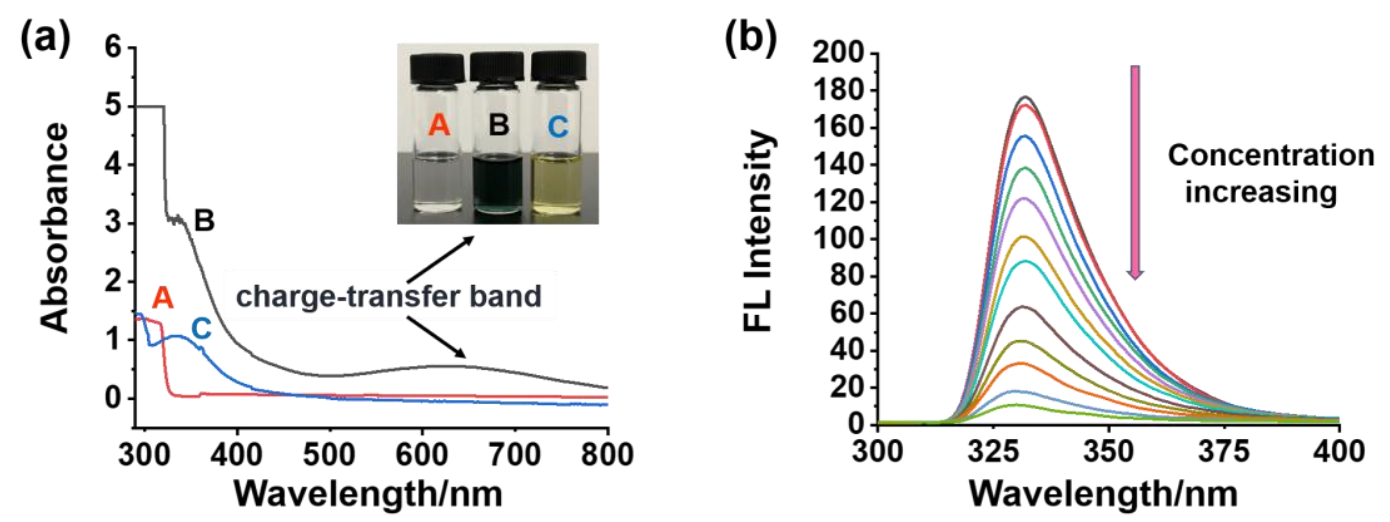

Figure S15. (a) UV-vis spectra (chloroform): A, EtP5 (0.01 M); B, TFB (0.03 M) in the presence of EtP5 (0.01 M); C, TFB (0.03 M). The inserted optical image shows the solution color change upon the formation of charge-transfer assemblies from EtP5 and TFB. (b) Fluorescence titration $\left(\lambda_{\mathrm{ex}}=280 \mathrm{~nm}\right)$ of EtP5 $(1.00 \mathrm{mM})$ in $\mathrm{CH}_{2} \mathrm{Cl}_{2}$ at room temperature upon a gradual increase in the concentration of TFB (from 0 to $5.95 \mathrm{mM}$ ). 

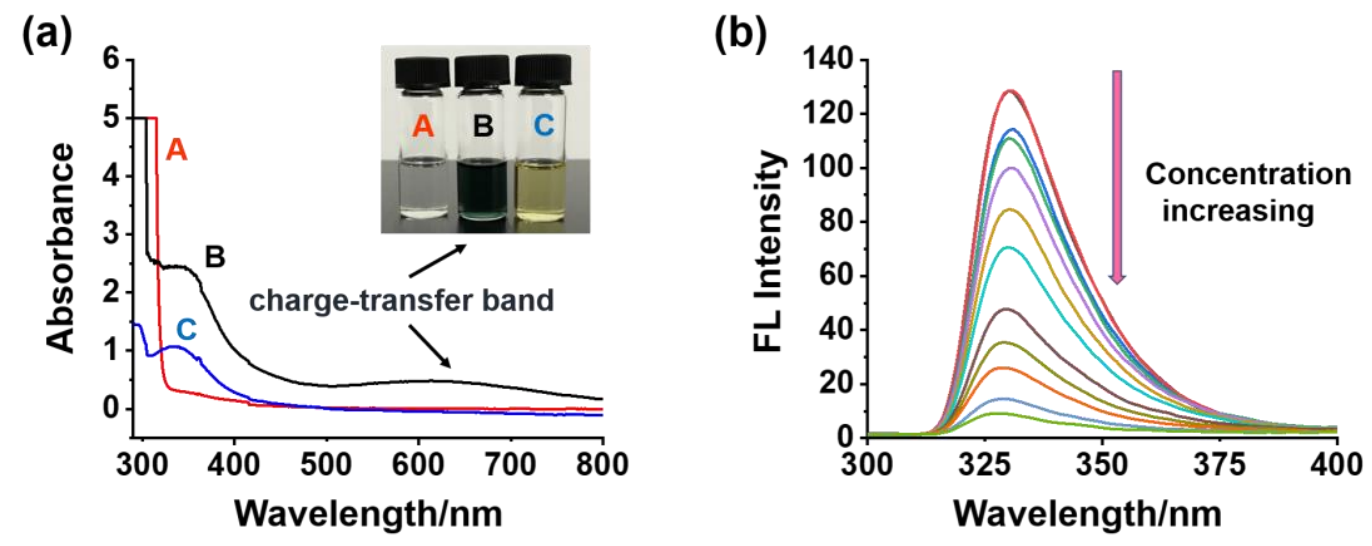

Figure S16. (a) UV-vis spectra (chloroform): A, EtP6 (0.01 M); B, TFB (0.03 M) in the presence of EtP6 (0.01 M); C, TFB (0.03 M). The inserted optical image shows the solution color change upon the formation of charge-transfer assemblies from EtP6 and TFB. (b) Fluorescence titration $\left(\lambda_{\mathrm{ex}}=280 \mathrm{~nm}\right)$ of EtP6 $(1.00 \mathrm{mM})$ in $\mathrm{CH}_{2} \mathrm{Cl}_{2}$ at room temperature upon a gradual increase in the concentration of TFB (from 0 to $5.95 \mathrm{mM}$ ). 


\section{Crystal engineering of the pillararenes-based co-crystals \\ a. Crystal structure of EtP5-TFB.}

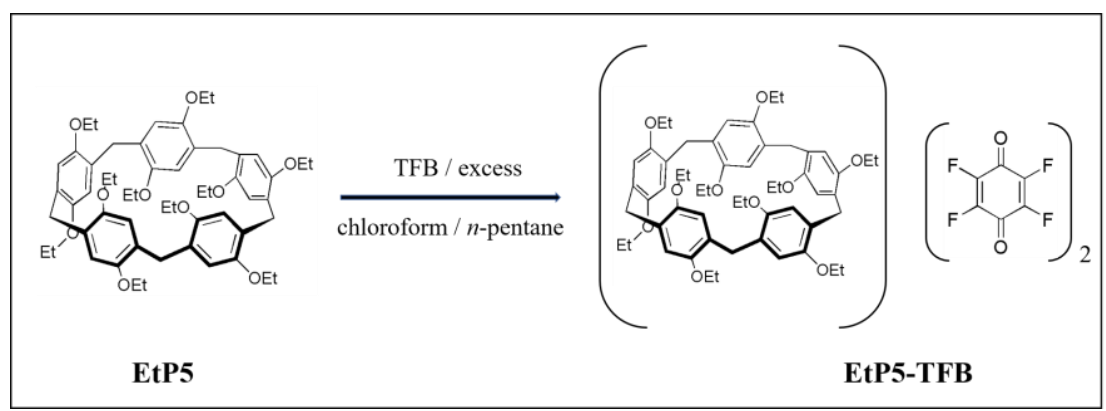

Scheme S1. Co-crystallization scheme of compound EtP5 with TFB to afford EtP5-TFB.

Dark green block crystals were obtained by $n$-pentane vapor diffusion into a $1 \mathrm{~mL}$ chloroform solution containing EtP5 (9 mg) and TFB (6 mg). The crystals were isolated for single crystal X-ray diffraction. The molar ratio of the EtP5 and TFB in the crystal structure was $1: 2$.

Crystal Data: For $\mathrm{C}_{72} \mathrm{H}_{82} \mathrm{~F}_{8} \mathrm{O}_{14}(\mathrm{M}=1323.37)$ : Monoclinic, space group $P 2{ }_{1} / c, a=$ 12.1938(6) $\AA, b=21.7578(10) \AA, c=27.4689(10) \AA, \alpha=\gamma=90^{\circ}, \beta=90.771(2)^{\circ}, V=$ $7287.1(6) \AA^{3}, Z=4, T=170.0 \mathrm{~K}, \mu(\mathrm{CuK} \alpha)=0.096 \mathrm{~mm}^{-1}, D_{\text {calc }}=1.206 \mathrm{~g} \mathrm{~cm}^{-3}, 45910$ reflections measured $\left(4.498^{\circ} \leq 2 \Theta \leq 49.998^{\circ}\right), 12812$ unique $\left(R_{\text {int }}=0.0734, R_{\text {sigma }}=\right.$ $0.0666)$ which were used in all calculations. The final $R_{1}$ was $0.1664(\mathrm{I}>2 \sigma(\mathrm{I}))$ and $w R_{2}$ was 0.3342 (all data). CCDC number: 1970419.

(a)

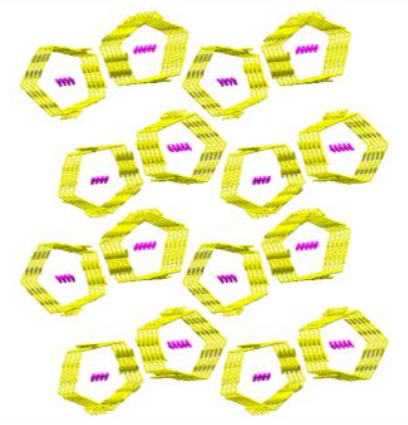

(b)

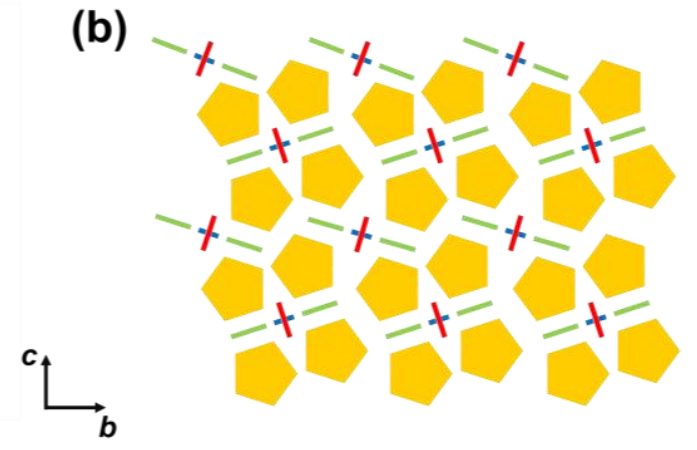

Figure S17. Crystal superstructure of EtP5-TFB. (a) Packing of EtP5 in the $b c$-plane with the $n$-pentane in the channels. TFB molecules are omitted. (b) Schematic representation of the layer-like superstructures formed on account of the packing of the EtP5-TFB in the $b c$-plane. The colors represent the symmetry equivalence and the hydrogen atoms are removed for the sake of clarity. 


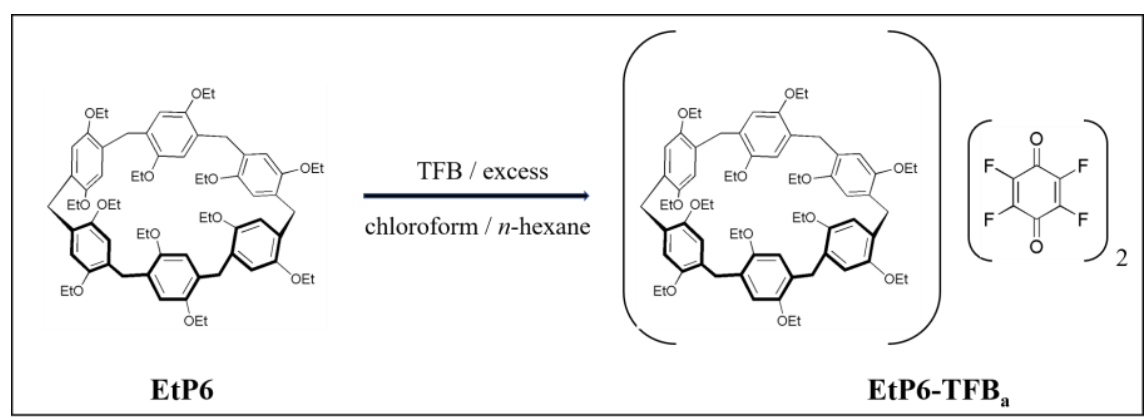

Scheme S2. Co-crystallization scheme of compound EtP6 with TFB to afford EtP6-TFBa.

Dark green crystals were obtained by $n$-hexane vapor diffusion into a $1 \mathrm{~mL}$ chloroform solution containing EtP6 (10 mg) and TFB (6 mg). The crystals were isolated for single crystal X-ray diffraction. The molar ratio of the EtP6 and TFB in the crystal structure was $1: 2$.

Crystal Data: For $\mathrm{C}_{78} \mathrm{H}_{84} \mathrm{~F}_{8} \mathrm{O}_{16}(\mathrm{M}=1429.45)$ : Triclinic, space group $P-1, a=$ 11.8651(12) $\mathrm{A}, b=13.1156(12) \AA, c=13.4869(13) \AA, \alpha=109.926(5)^{\circ}, \beta=$ $91.148(5)^{\circ}, \gamma=112.668(5)^{\circ}, V=1792.8(3) \AA^{3}, Z=1, T=150.0 \mathrm{~K}, \mu(\mathrm{CuK} \alpha)=0.105$ $\mathrm{mm}^{-1}, D_{\text {calc }}=1.324 \mathrm{~g} \mathrm{~cm}^{-3}, 25897$ reflections measured $\left(4.54^{\circ} \leq 2 \Theta \leq 49.998^{\circ}\right), 6079$ unique $\left(R_{\text {int }}=0.0966, R_{\text {sigma }}=0.0792\right)$ which were used in all calculations. The final $R_{1}$ was $0.1446(\mathrm{I}>2 \sigma(\mathrm{I}))$ and $w R_{2}$ was 0.1781 (all data). CCDC number: 2033910. 


\section{(a)}

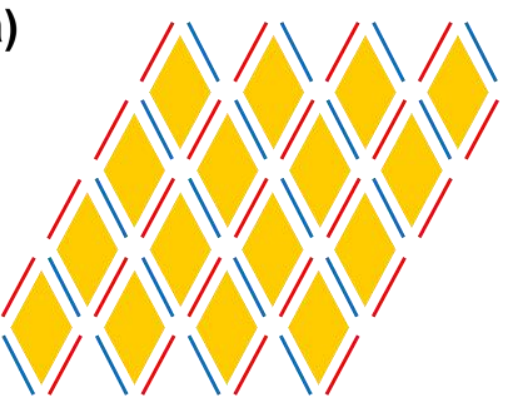

(b) Propagation of DA interactions along with $b$-axis

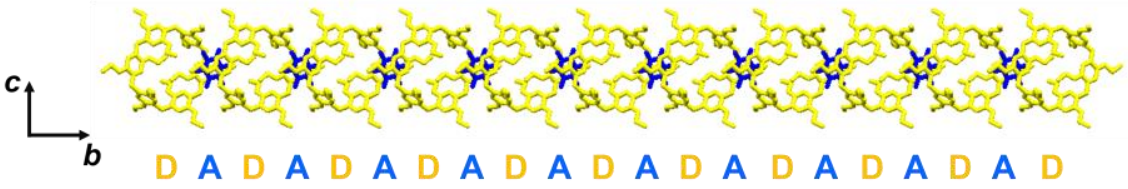

(c) Propagation of $\mathrm{C}-\mathrm{H} \cdots \pi$ interactions along with $\mathrm{c}$-axis

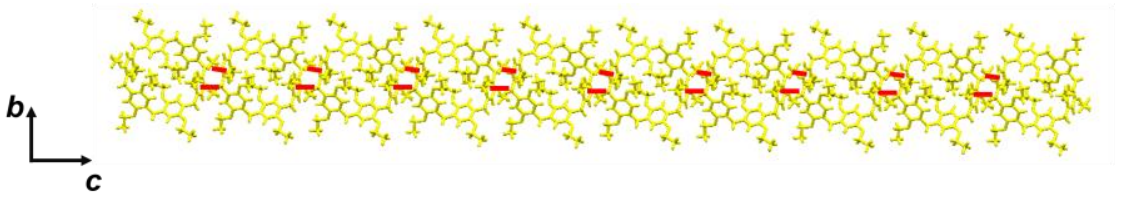

Figure S18. Crystal superstructure of EtP6-TFBa. (a) Schematic representation of the packing of EtP6 and TFB in the $a b$-plane through CT interactions. (b) Propagation of DA interactions in the $b c$-plane. (c) Propagation of $\mathrm{C}-\mathrm{H}^{\cdots} \pi \pi$ interaction along the $c$-axis. Red lines represent $\mathrm{C}-\mathrm{H} \cdots \pi$ interactions between hydrogen atoms of the methylene bridges on EtP6 molecules and benzene rings, propagating along the $c$-axis. $\mathrm{C}-\mathrm{H} \cdots \pi$ interaction parameters: $\mathrm{H} \cdots \pi$-plane distance $(\AA), \mathrm{C}-\mathrm{H} \cdots \pi$ angle (deg): $2.67,149.70$. The colors represent the symmetry equivalence and hydrogen atoms in part of the figures are removed for the sake of clarity. 
c. Crystal structure of EtP6-TFB .

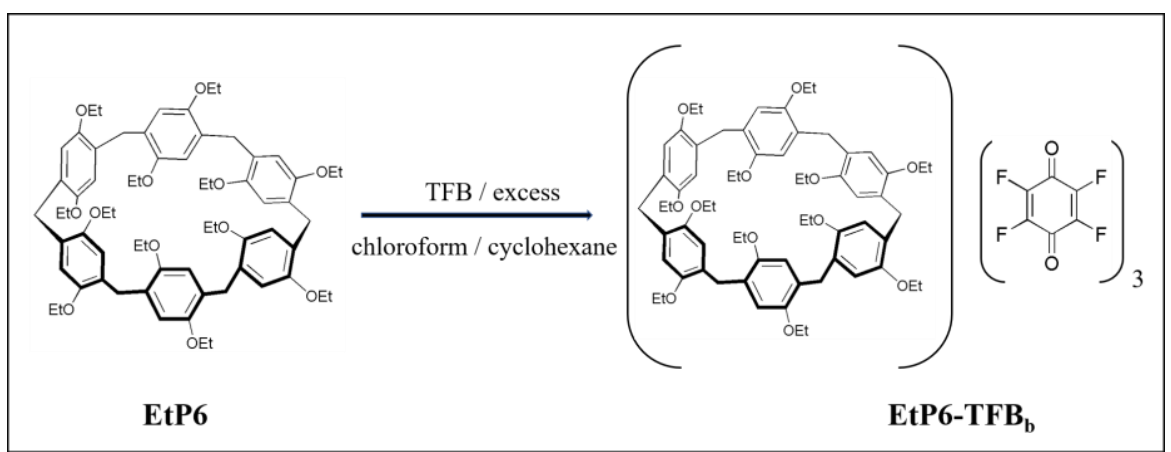

Scheme S3. Co-crystallization scheme of compound EtP6 with TFB to afford EtP6-TFB

Dark green crystals were obtained by cyclohexane vapor diffusion into a $1 \mathrm{~mL}$ chloroform solution containing EtP6 (10 mg) and TFB (6 mg). The crystals were isolated for single crystal X-ray diffraction. The molar ratio of the EtP6 and TFB in the crystal structure was $1: 3$.

Crystal Data: For $\mathrm{C}_{49} \mathrm{H}_{55} \mathrm{Cl}_{3} \mathrm{~F}_{6} \mathrm{O}_{9}(\mathrm{M}=1008.28)$ : Monoclinic, space group $C 2 / c, a=$ 16.592(3) $\mathrm{A}, b=28.589(7) \AA, c=22.413(4) \AA, \alpha=\gamma=90^{\circ}, \beta=108.118(6)^{\circ}, V=$ $10105(4) \AA^{3}, Z=8, T=170.0 \mathrm{~K}, \mu(\mathrm{CuK} \alpha)=0.256 \mathrm{~mm}^{-1}, D_{\text {calc }}=1.326 \mathrm{~g} \mathrm{~cm}^{-3}, 38966$ reflections measured $\left(4.77^{\circ} \leq 2 \Theta \leq 49.998^{\circ}\right), 8867$ unique $\left(R_{\text {int }}=0.0344, R_{\text {sigma }}=\right.$ $0.0256)$ which were used in all calculations. The final $R_{1}$ was $0.1040(\mathrm{I}>2 \sigma(\mathrm{I}))$ and $w R_{2}$ was 0.2651 (all data). CCDC number: 1970420. 
(a)

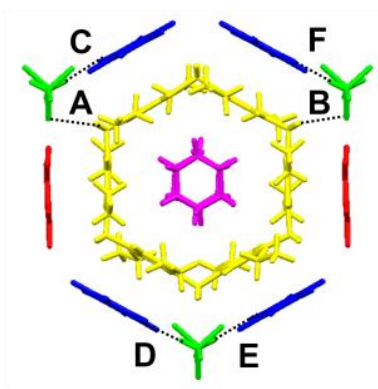

Top view

(b)

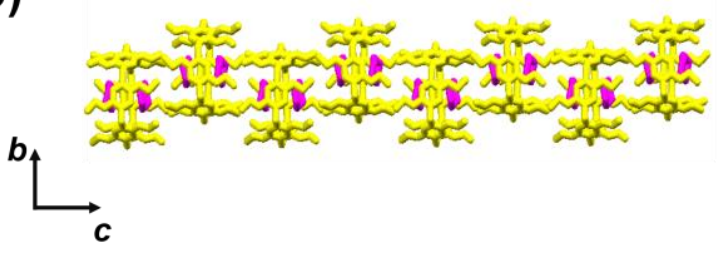

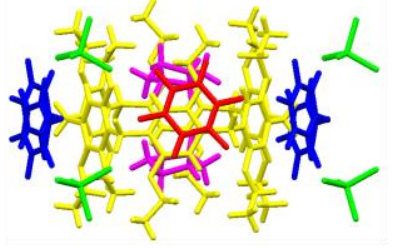

Side view

(c)

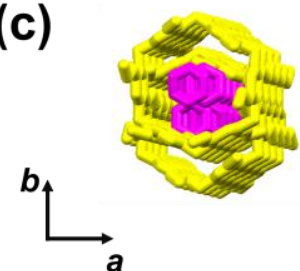

(d)

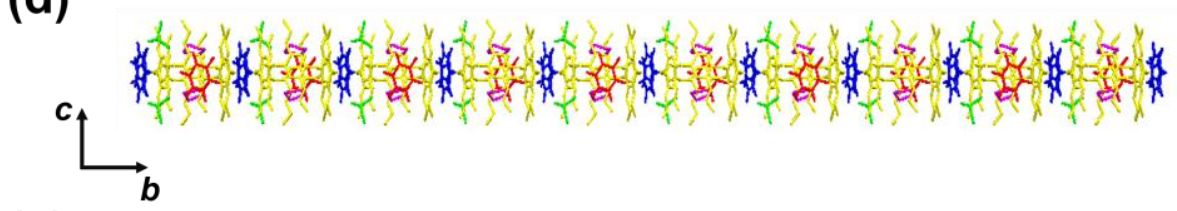

(e)

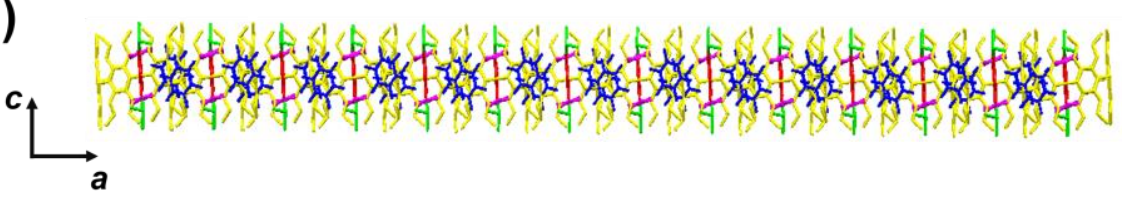

Figure S19. Crystal superstructure of EtP6-TFB . (a) Top view and side view of regular hexagonal EtP6 unit and TFB molecules around each side of the hexagons and two cyclohexane molecules inside the cavity. Black dashed lines indicate the existence of $\mathrm{C}-\mathrm{H} \cdots \mathrm{Cl}$ interactions $(\mathbf{A}$ and $\mathbf{B})$ and $\mathrm{C}-\mathrm{H} \cdots \mathrm{F}$ interactions $(\mathbf{C}, \mathbf{D}, \mathbf{E}$ and $\mathbf{F}) \cdot \mathrm{C}-\mathrm{H} \cdots \mathrm{Cl}$ parameters are as follows: $\mathrm{C}-\mathrm{H} \cdots \mathrm{Cl}$ distances $(\AA)$ : A, 2.92; B, 2.92. $\mathrm{C}-\mathrm{H} \cdots \mathrm{Cl}$ angles (deg): A, 132.33; B, 132.33. C-H $\cdots \mathrm{F}$ interaction parameters: $\mathrm{C}-\mathrm{H} \cdots \mathrm{F}$ distances $(\AA)$ : C, 2.38; D, 2.38; E, 2.38; F, 2.38. C-H $\cdots$ F angles (deg): C, 169.54; D, 169.54; E, 169.54; F, 169.54. (b, c) EtP6 units are staggered along $c$-axis without forming channels. (d) View of the layer-like superstructure in the $b c$-plane. (e) View of the layer-like superstructure in the $a c$-plane. The colors represent the symmetry equivalence and hydrogen atoms are removed for the sake of clarity. 


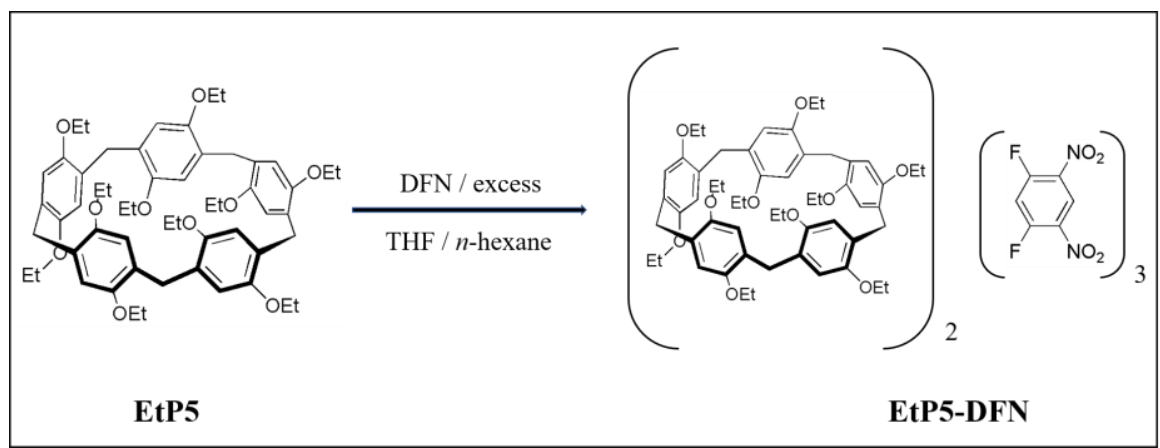

Scheme S4. Co-crystallization scheme of compound EtP5 with DFN to afford EtP5-DFN.

Orange red crystals were obtained by $n$-hexane vapor diffusion into a $1 \mathrm{~mL}$ THF solution containing EtP5 ( $9 \mathrm{mg}$ ) and DFN (7 mg). The crystals were isolated for single crystal X-ray diffraction. The molar ratio of the EtP5 and DFN in the crystal structure was $1: 1.5$.

Crystal Data of EtP5-DFN: For $\mathrm{C}_{72} \mathrm{H}_{88} \mathrm{~F}_{3} \mathrm{~N}_{3} \mathrm{O}_{16.5}(\mathrm{M}=1316.45)$ : Monoclinic, space group $C 2 / c, a=48.022(2) \AA, b=11.8130(6) \AA, c=27.2202(12) \AA, \alpha=\gamma=90^{\circ}, \beta=$ $111.656(2)^{\circ}, V=14351.6(12) \AA^{3}, Z=8, T=296.15 \mathrm{~K}, \mu(\mathrm{CuK \alpha})=0.091 \mathrm{~mm}^{-1}, D_{\text {calc }}=$ $1.219 \mathrm{~g} \mathrm{~cm}^{-3}, 52811$ reflections measured $\left(4.05^{\circ} \leq 2 \Theta \leq 55.026^{\circ}\right), 16154$ unique $\left(R_{\text {int }}\right.$ $\left.=0.0512, R_{\text {sigma }}=0.0543\right)$ which were used in all calculations. The final $R_{1}$ was $0.0991(\mathrm{I}>2 \sigma(\mathrm{I}))$ and $w R_{2}$ was 0.1927 (all data). CCDC number: 2033911. 


\section{(a)}

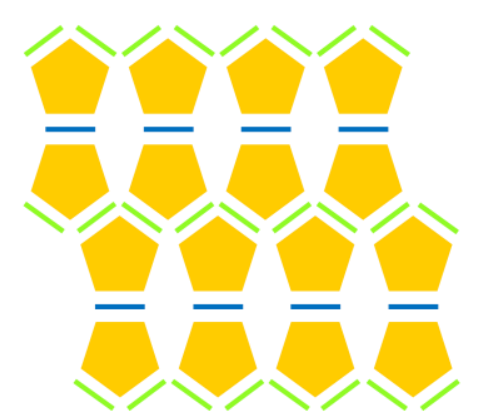

(b)

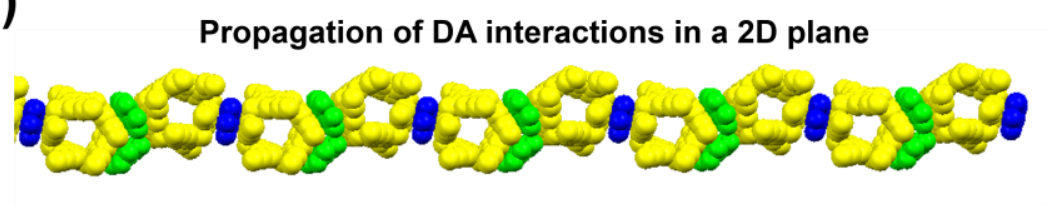

(c) Propagation of $\mathrm{C}-\mathrm{H} \cdots \pi$ interactions in a 2D plane

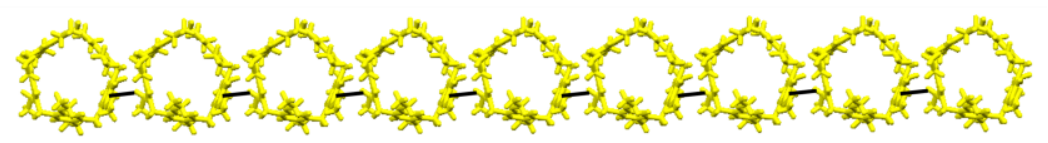

Figure S20. Crystal superstructure of EtP5-DFN. (a) Schematic representation of the arrangement of EtP5 and DFN molecules in a plane through a 2D network of CT interactions. (b) Propagation of donor-acceptor (DA) interactions in a 2D plane. (c) Propagation of $\mathrm{C}-\mathrm{H} \cdots \pi$ interactions in a $2 \mathrm{D}$ plane. Black lines represent $\mathrm{C}-\mathrm{H} \cdots \pi$ interactions between hydrogen atoms of the ethoxy groups on EtP5 molecules and benzene rings. $\mathrm{C}-\mathrm{H} \cdots \pi$ interaction parameters: $\mathrm{H} \cdots \pi$-plane distance $(\AA), \mathrm{C}-\mathrm{H} \cdots \pi$ angle (deg): $2.98,139.35$. Hydrogen atoms in part of the figures are removed for the sake of clarity. 
e. Crystal structure of EtP6-DFNa.

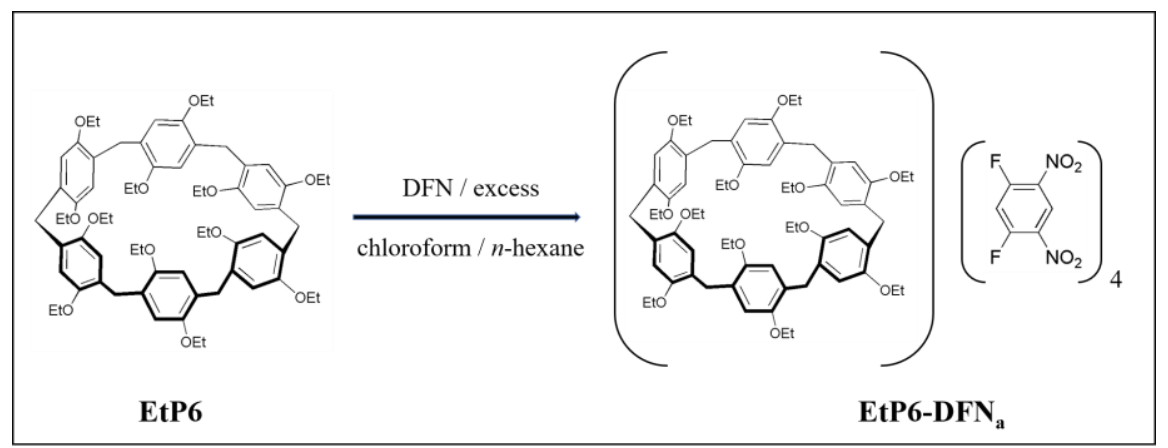

Scheme S5. Co-crystallization scheme of compound EtP6 with DFN to afford EtP6-DFNa.

Orange red crystals were obtained by $n$-hexane vapor diffusion into a $1 \mathrm{~mL}$ chloroform solution containing EtP6 (10 mg) and DFN (7 mg). The crystals were isolated for single crystal X-ray diffraction. The molar ratio of the EtP6 and DFN in the crystal structure was $1: 4$.

Crystal Data of EtP6-DFNa: For $\mathrm{C}_{92} \mathrm{H}_{93} \mathrm{Cl}_{6} \mathrm{~F}_{8} \mathrm{~N}_{8} \mathrm{O}_{28}$ ( $\left.\mathrm{M}=2123.44\right)$ : Monoclinic, space group $P 2{ }_{1} / c, a=16.3839(9) \AA, b=29.3585(19) \AA, c=22.1119(13) \AA, \alpha=\gamma=$ $90^{\circ}, \beta=109.228(2)^{\circ}, V=10042.6(10) \AA^{3}, Z=4, T=150.0 \mathrm{~K}, \mu(\mathrm{CuK} \alpha)=0.265 \mathrm{~mm}^{-1}$, $D_{\text {calc }}=1.404 \mathrm{~g} \mathrm{~cm}^{-3}, 90009$ reflections measured $\left(4.142^{\circ} \leq 2 \Theta \leq 50^{\circ}\right), 17351$ unique $\left(R_{\text {int }}=0.0545, R_{\text {sigma }}=0.0417\right)$ which were used in all calculations. The final $R_{1}$ was $0.1295(\mathrm{I}>2 \sigma(\mathrm{I}))$ and $w R_{2}$ was 0.3097 (all data). CCDC number: 2033913. 
(a)

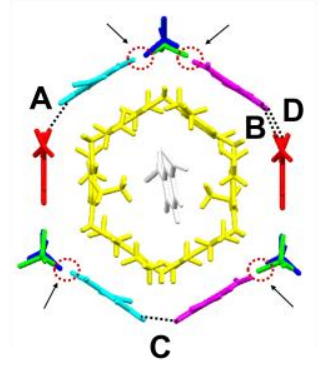

(b)

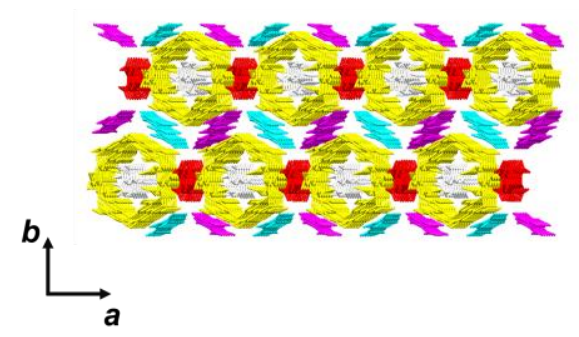

(c)
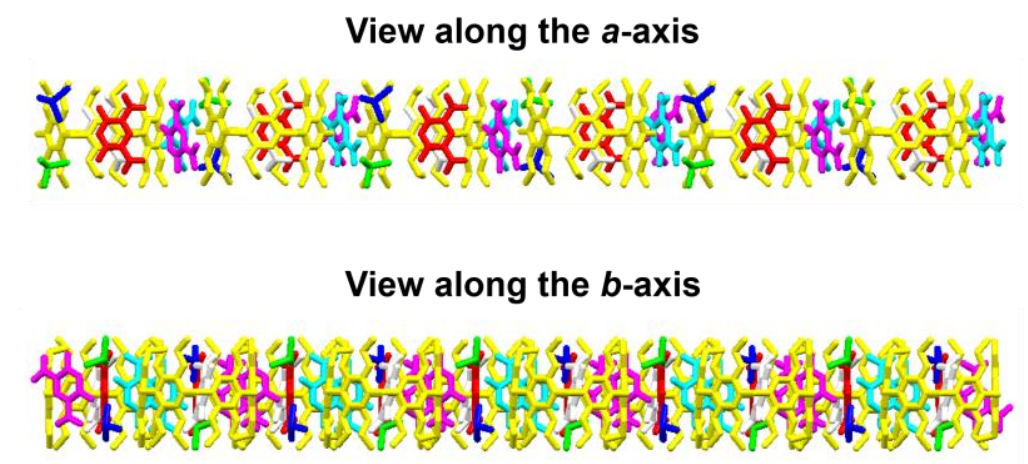

Figure S21. Crystal superstructure of EtP6-DFNa. (a) Top view of regular hexagonal EtP6-DFNa. Black dashed lines represent $\mathrm{C}-\mathrm{H} \cdots \mathrm{O}$ interactions $(\mathbf{A}$ and $\mathbf{B})$ and $\mathrm{C}-\mathrm{H} \cdots \mathrm{F}$ interactions ( $\mathbf{C}$ and $\mathbf{D})$ existing between DFN molecules. $\mathrm{C}-\mathrm{H} \cdots \mathrm{O}$ parameters are as follows: $\mathrm{C}-\mathrm{H} \cdots \mathrm{O}$ distances $(\AA)$ : A, 2.44; B, 2.41. $\mathrm{C}-\mathrm{H} \cdots \mathrm{O}$ angles (deg): A, 153.70; B, 143.49. $\mathrm{C}-\mathrm{H} \cdots \mathrm{F}$ interaction parameters: $\mathrm{C}-\mathrm{H} \cdots \mathrm{F}$ distances $(\AA)$ : C, 2.62; D, 2.43. C-H $\cdots \mathrm{F}$ angles (deg): C, 125.59; D, 149.60. Red dashed circles represent the existence of multiple $\mathrm{C}-\mathrm{H} \cdots \mathrm{O}$ and $\mathrm{C}-\mathrm{H} \cdots \mathrm{Cl}$ interactions between DFN and $\mathrm{CHCl}_{3}$ molecules. (b) Packing of EtP6 and DFN in the $a b$-plane with the one kind of $\mathbf{D F N}$ in the channels. $\mathrm{CHCl}_{3}$ molecules are omitted. (c) View of the layer-like superstructure along $a$ and $b$-axis. Hydrogen atoms in part of the figures are removed for the sake of clarity. 


\section{f. Crystal structure of EtP6-DFNb.}

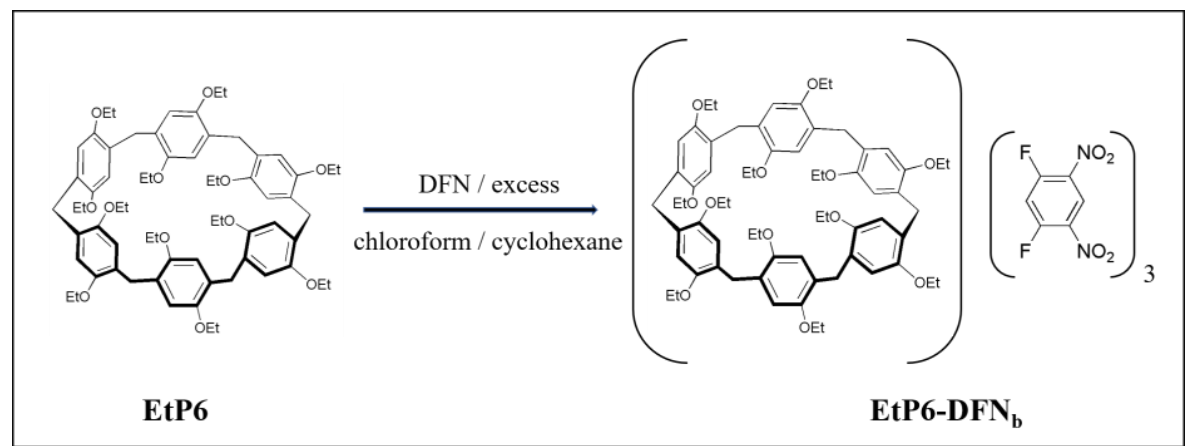

Scheme S6. Co-crystallization scheme of compound EtP6 with DFN to afford EtP6-DFNb.

Orange red crystals were obtained by cyclohexane vapor diffusion into a $1 \mathrm{~mL}$ chloroform solution containing EtP6 (10 mg) and DFN (7 mg). The crystals were isolated for single crystal X-ray diffraction. The molar ratio of the EtP6 and DFN in the crystal structure was $1: 3$.

Crystal Data of EtP6-DFNo: For $\mathrm{C}_{98} \mathrm{H}_{116} \mathrm{Cl}_{6} \mathrm{~F}_{6} \mathrm{~N}_{6} \mathrm{O}_{24}(\mathrm{M}=2088.66)$ : Monoclinic, space group $C 2 / c, a=16.6113(10) \AA, b=28.978(2) \AA, c=22.5547(17) \AA, \alpha=\gamma=$ $90^{\circ}, \beta=105.811(2)^{\circ}, V=10446.4(13) \AA^{3}, Z=4, T=150.01 \mathrm{~K}, \mu(\mathrm{CuK} \alpha)=0.248$ $\mathrm{mm}^{-1}, D_{\text {calc }}=1.328 \mathrm{~g} \mathrm{~cm}^{-3}, 61991$ reflections measured $\left(4.166^{\circ} \leq 2 \Theta \leq 50^{\circ}\right), 9180$ unique ( $\left.R_{\text {int }}=0.0641, R_{\text {sigma }}=0.0432\right)$ which were used in all calculations. The final $R_{1}$ was 0.1500 (I $\left.>2 \sigma(\mathrm{I})\right)$ and $w R_{2}$ was 0.3624 (all data). CCDC number: 2033912.

(a)

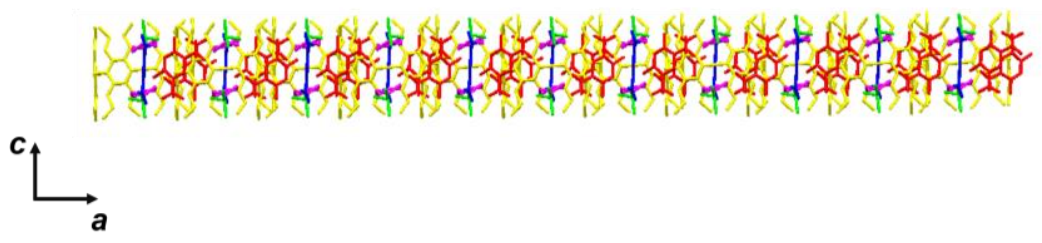

(b)

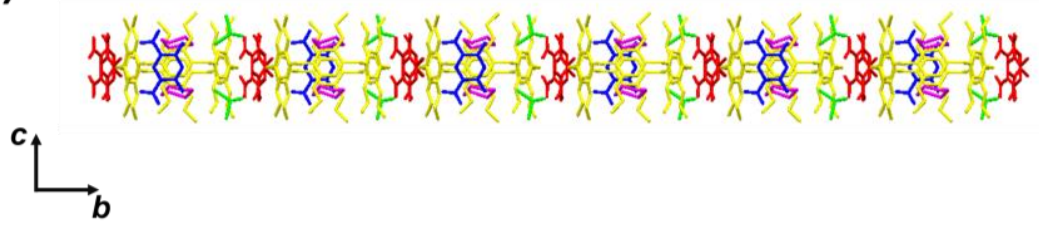

Figure S22. Crystal superstructure of EtP6-DFN $\mathbf{N}_{\mathbf{b}}$. (a) View of the layer-like superstructure in the $a c$-plane. (b) View of the layer-like superstructure in the $b c$-plane. Hydrogen atoms are removed for the sake of clarity. 
Table S1. Experimental crystallographic data for the co-crystals of EtP5-TFB, EtP6-TFBa and EtP6-TFB

\begin{tabular}{|c|c|c|c|}
\hline Parameters & EtP5-TFB & EtP6-TFB $_{a}$ & EtP6-TFB $_{b}$ \\
\hline Formula & $\mathrm{C}_{72} \mathrm{H}_{82} \mathrm{~F}_{8} \mathrm{O}_{14}$ & $\mathrm{C}_{78} \mathrm{H}_{84} \mathrm{~F}_{8} \mathrm{O}_{16}$ & $\mathrm{C}_{49} \mathrm{H}_{55} \mathrm{Cl}_{3} \mathrm{~F}_{6} \mathrm{O}_{9}$ \\
\hline FW & 1323.37 & 1429.45 & 1008.28 \\
\hline Temp. (K) & 170.0 & 150.0 & 170.0 \\
\hline Crystal system & Monoclinic & Triclinic & Monoclinic \\
\hline Space group & $P 2_{1} / c$ & $P-1$ & $\mathrm{C} 2 / \mathrm{c}$ \\
\hline$a(\AA)$ & $12.1938(6)$ & $11.8651(12)$ & $16.592(3)$ \\
\hline$b(\AA)$ & $21.7578(10)$ & $13.1156(12)$ & $28.589(7)$ \\
\hline$c(\AA)$ & $27.4689(10)$ & $13.4869(13)$ & $22.413(4)$ \\
\hline$a\left(^{\circ}\right)$ & 90 & $109.926(5)$ & 90 \\
\hline$\beta\left(^{\circ}\right)$ & $90.771(2)$ & $91.148(5)$ & $108.118(6)$ \\
\hline$\gamma\left(\left(^{\circ}\right)\right.$ & 90 & $112.668(5)$ & 90 \\
\hline Volume $\left(\AA^{3}\right)$ & $7287.1(6)$ & $1792.8(3)$ & $10105(4)$ \\
\hline$Z$ & 4 & 1 & 8 \\
\hline$\rho_{\text {calc }}\left(\mathrm{g} \mathrm{cm}^{-3}\right)$ & 1.206 & 1.324 & 1.326 \\
\hline$F(000)$ & 2792.0 & 752.0 & 4208.0 \\
\hline $\begin{array}{l}\text { Independent } \\
\text { reflections }\end{array}$ & $\begin{array}{l}12812 \\
{\left[R_{\text {int }}=0.0734,\right.} \\
\left.R_{\text {sigma }}=0.0666\right]\end{array}$ & $\begin{array}{l}6079 \\
{\left[R_{\text {int }}=0.0966,\right.} \\
\left.R_{\text {sigma }}=0.0792\right]\end{array}$ & $\begin{array}{l}8867 \\
{\left[R_{\text {int }}=0.0344,\right.} \\
\left.R_{\text {sigma }}=0.0256\right]\end{array}$ \\
\hline $\begin{array}{l}\text { Goodness-of-fit } \\
\text { on } F^{2}\end{array}$ & 1.069 & 1.057 & 1.020 \\
\hline $\begin{array}{l}\text { Final } R \text { indexes } \\
\qquad[I>=2 \sigma(I)]\end{array}$ & $\begin{array}{l}R_{1}=0.0985 \\
w R_{2}=0.2688\end{array}$ & $\begin{array}{l}R_{1}=0.0738 \\
w R_{2}=0.1421\end{array}$ & $\begin{array}{l}R_{1}=0.0844 \\
w R_{2}=0.2397\end{array}$ \\
\hline $\begin{array}{l}\text { Final } R \text { indexes } \\
\quad \text { [all data }]\end{array}$ & $\begin{array}{l}R_{1}=0.1664 \\
w R_{2}=0.3342\end{array}$ & $\begin{array}{l}R_{1}=0.1446 \\
w R_{2}=0.1781\end{array}$ & $\begin{array}{l}R_{1}=0.1040 \\
w R_{2}=0.2651\end{array}$ \\
\hline $\begin{array}{l}\text { Largest diff. } \\
\text { peak/hole } \\
\left(\mathrm{e} \AA^{-3}\right)\end{array}$ & $1.08 /-0.56$ & $0.70 /-0.36$ & $0.70 /-1.08$ \\
\hline
\end{tabular}


Table S2. Experimental crystallographic data for the co-crystals of EtP5-DFN, EtP6-DFNa and EtP6-DFN

\begin{tabular}{|c|c|c|c|}
\hline Parameters & EtP5-DFN & EtP6-DFN $_{a}$ & EtP6-DFN $_{b}$ \\
\hline Formula & $\mathrm{C}_{72} \mathrm{H}_{88} \mathrm{~F}_{3} \mathrm{~N}_{3} \mathrm{O}_{16.5}$ & $\begin{array}{l}\mathrm{C}_{92} \mathrm{H}_{93} \mathrm{Cl}_{6} \mathrm{~F}_{8} \mathrm{~N}_{8} \\
\mathrm{O}_{28}\end{array}$ & $\begin{array}{l}\mathrm{C}_{98} \mathrm{H}_{116} \mathrm{Cl}_{6} \mathrm{~F}_{6} \mathrm{~N}_{6} \\
\mathrm{O}_{24}\end{array}$ \\
\hline $\mathrm{FW}$ & 1316.45 & 2123.44 & 2088.66 \\
\hline Temp. (K) & 296.15 & 150.0 & 150.01 \\
\hline Crystal system & Monoclinic & Monoclinic & Monoclinic \\
\hline Space group & $\mathrm{C} 2 / \mathrm{c}$ & $P 2_{1} / c$ & $\mathrm{C} 2 / \mathrm{c}$ \\
\hline$a(\AA)$ & $48.022(2)$ & $16.3839(9)$ & $16.6113(10)$ \\
\hline$b(\AA)$ & $11.8130(6)$ & $29.3585(19)$ & $28.978(2)$ \\
\hline$c(\AA)$ & $27.2202(12)$ & $22.1119(13)$ & $22.5547(17)$ \\
\hline$a\left(^{\circ}\right)$ & 90 & 90 & 90 \\
\hline$\beta\left(^{\circ}\right)$ & $111.656(2)$ & $109.228(2)$ & $105.811(2)$ \\
\hline$\gamma\left({ }^{\circ}\right)$ & 90 & 90 & 90 \\
\hline Volume $\left(\AA^{3}\right)$ & 14351.6(12) & $10042.6(10)$ & 10446.4(13) \\
\hline$Z$ & 8 & 4 & 4 \\
\hline$\rho_{\text {calc }}\left(\mathrm{g} \mathrm{cm}^{-3}\right)$ & 1.219 & 1.404 & 1.328 \\
\hline$F(000)$ & 5600.0 & 4396.0 & 4376.0 \\
\hline $\begin{array}{l}\text { Independent } \\
\text { reflections }\end{array}$ & $\begin{array}{l}16154 \\
{\left[R_{\text {int }}=0.0512,\right.} \\
\left.R_{\text {sigma }}=0.0543\right]\end{array}$ & $\begin{array}{l}17351 \\
{\left[R_{\mathrm{int}}=0.0545,\right.} \\
\left.R_{\text {sigma }}=0.0417\right]\end{array}$ & $\begin{array}{l}9180 \\
{\left[R_{\text {int }}=0.0641,\right.} \\
\left.R_{\text {sigma }}=0.0432\right]\end{array}$ \\
\hline $\begin{array}{l}\text { Goodness-of-fit on } \\
F^{2}\end{array}$ & 1.036 & 1.022 & 1.092 \\
\hline $\begin{array}{l}\text { Final } \quad R \quad \text { indexes } \\
{[I \geq 2 \sigma(I)]}\end{array}$ & $\begin{array}{l}R_{1}=0.0657 \\
w R_{2}=0.1703\end{array}$ & $\begin{array}{l}R_{1}=0.0935 \\
w R_{2}=0.2667\end{array}$ & $\begin{array}{l}R_{1}=0.1132, \\
w R_{2}=0.3214\end{array}$ \\
\hline $\begin{array}{l}\text { Final } R \text { indexes } \\
\text { [all data] }\end{array}$ & $\begin{array}{l}R_{1}=0.0991 \\
w R_{2}=0.1927\end{array}$ & $\begin{array}{l}R_{1}=0.1295 \\
w R_{2}=0.3097\end{array}$ & $\begin{array}{l}R_{1}=0.1500 \\
w R_{2}=0.3624\end{array}$ \\
\hline $\begin{array}{l}\text { Largest diff. } \\
\text { peak/hole }\left(\mathrm{e} \AA^{-3}\right)\end{array}$ & $0.61 /-0.54$ & $1.31 /-0.62$ & $1.44 /-0.93$ \\
\hline
\end{tabular}




\section{References}

S1. Hu, X.; Chen, Z.; Chen, L.; Zhang, L.; Hou, J.; Li, Z. Pillar[ $n]$ arenes $(n=8-10)$ with Two Cavities: Synthesis, Structures and Complexing Properties. Chem. Commun. 2012, 48, 10999-11001.

S2. Jie, K.; Liu, M.; Zhou, Y.; Little, M.; Pulido, A.; Chong, S.; Stephenson, A.; Hughes, A.; Sakakibara, F.; Ogoshi, T.; Blanc, F.; Day, G.; Huang, F.; Cooper, A. Near-Ideal Xylene Selectivity in Adaptive Molecular Pillar $[n]$ arene Crystals. J. Am. Chem. Soc. 2018, 140, 6921-6930.

S3. Lu, T.; Chen, F. Multiwfn: A Multifunctional Wavefunction Analyzer. J. Comput. Chem. 2012, $33,580-592$.

S4. Chiu, C.; Wu, H.; Yao, Z.; Zhou, F.; Zhang, H.; Ozolins, V.; Huang, Y. Facet-Selective Adsorption on Noble Metal Crystals Guided by Electrostatic Potential Surfaces of Aromatic Molecules. J. Am. Chem. Soc. 2013, 135, 15489-15500. 